\title{
Development of Methane and Nitrous Oxide Emission Factors for the Biomass Fired Circulating Fluidized Bed Combustion Power Plant
}

\author{
Chang-Sang Cho, ${ }^{1}$ Jae-Hwan Sa, ${ }^{2}$ Ki-Kyo Lim, ${ }^{1}$ Tae-Mi Youk, ${ }^{3}$ Seung-Jin Kim, ${ }^{1}$ \\ Seul-Ki Lee, ${ }^{1}$ and Eui-Chan Jeon ${ }^{2}$ \\ ${ }^{1}$ Cooperate Course for Climate Change, Sejong University, Seoul, Republic of Korea \\ ${ }^{2}$ Department of Environment and Energy, Sejong University, Seoul 143-747, Republic of Korea \\ ${ }^{3}$ Department of Statistics, Korea University, Seoul, Republic of Korea
}

Correspondence should be addressed to Eui-Chan Jeon, ecjeon@sejong.ac.kr

Received 2 August 2012; Accepted 22 November 2012

Academic Editors: M. Faulstich and X. Jiang

Copyright (c) 2012 Chang-Sang Cho et al. This is an open access article distributed under the Creative Commons Attribution License, which permits unrestricted use, distribution, and reproduction in any medium, provided the original work is properly cited.

This study makes use of this distinction to analyze the exhaust gas concentration and fuel of the circulating fluidized bed (CFB) boiler that mainly uses wood biomass, and to develop the emission factors of Methane $\left(\mathrm{CH}_{4}\right)$, Nitrous oxide $\left(\mathrm{N}_{2} \mathrm{O}\right)$. The fuels used as energy sources in the subject working sites are Wood Chip Fuel (WCF), RDF and Refused Plastic Fuel (RPF) of which heating values are $11.9 \mathrm{TJ} / \mathrm{Gg}, 17.1 \mathrm{TJ} / \mathrm{Gg}$, and $31.2 \mathrm{TJ} / \mathrm{Gg}$, respectively. The average concentrations of $\mathrm{CH}_{4}$ and $\mathrm{N}_{2} \mathrm{O}$ were measured to be $2.78 \mathrm{ppm}$ and $7.68 \mathrm{ppm}$, respectively. The analyzed values and data collected from the field survey were used to calculate the emission factor of $\mathrm{CH}_{4}$ and $\mathrm{N}_{2} \mathrm{O}$ exhausted from the CFB boiler. As a result, the emission factors of $\mathrm{CH}_{4}$ and $\mathrm{N}_{2} \mathrm{O}$ are $1.4 \mathrm{~kg} / \mathrm{TJ}(0.9-1.9 \mathrm{~kg} / \mathrm{TJ})$ and $4.0 \mathrm{~kg} / \mathrm{TJ}(2.9-5.3 \mathrm{~kg} / \mathrm{TJ})$ within a $95 \%$ confidence interval. Biomass combined with the combustion technology for the CFB boiler proved to be more effective in reducing the $\mathrm{N}_{2} \mathrm{O}$ emission, compared to the emission factor of the CFB boiler using fossil fuel.

\section{Introduction}

The greenhouse gas emissions causing global warming have been consistently rising since the Industrial Revolution, increasing up to $70 \%$ between 1970 and 2004 worldwide. If this trend continues, the average temperature of the Earth by the end of the 21 st century is expected to rise by up to $6.4^{\circ} \mathrm{C}$ [1], compared to present averages. To resolve this problem, each country in the world is establishing and implementing national plans to lower greenhouse gas emission. As a part of the efforts, the global community ratified the Kyoto Protocol at the Conference of the Parties, held in Kyoto in 1997. The protocol suggested $5.2 \%$ of reduction in greenhouse gas emission between 2008 and 2012, the first targeting period, compared to that of 1990 [2]. Korea also announced 30\% reduction target compared to Business As Usual (BAU) by 2020 , to reduce greenhouse gas emission. This target is quite a forward-looking goal for a non-Annex country of the Kyoto Protocol that is not required to lower emission [3].

To effectively achieve the reduction goal, the most essential aim is the figuring out of the national emission of greenhouse gas and developing emission inventory based on rational data. As for non- $\mathrm{CO}_{2}$ emission, the global warming potential (GWP) of methane $\left(\mathrm{CH}_{4}\right)$ and nitrous oxide $\left(\mathrm{N}_{2} \mathrm{O}\right)$ is 21 and 310 times that of carbon dioxide $\left(\mathrm{CO}_{2}\right)$, respectively, which should not be overlooked in developing the inventory. The emission characteristics of the non- $\mathrm{CO}_{2}$ greenhouse gas fluctuate according to several factors such as type of emission source, type and property of fuel, form of boiler, type of prevention facility, and load factor $[4,5]$.

Therefore, Intergovernmental Panel on Climate Change (IPCC) recommends the application of country-specific or technology-specific emission factors instead of the Tier 1 default emission factor, when each country calculates its 
own greenhouse gas emission [6]. However, most R\&D on emission factors of energy sector both domestic and international was carried out for $\mathrm{CO}_{2}$ rather than non- $\mathrm{CO}_{2}$ $[7,8]$.

This study develops the emission factor of non- $\mathrm{CO}_{2}$ gas released from combined heat and power plants that use biomass. Using biomass as an energy source does not influence the increase of $\mathrm{CO}_{2}$ in the air because the $\mathrm{CO}_{2}$ absorbed in the process of photosynthesis goes back to the air when the biomass is used [9]. The biomass substituting fossil fuel has the effect of lowering the greenhouse gas emission by the increase in the emission that would have generated due to the combustion of fossil fuel [10]. However, the emission of non- $\mathrm{CO}_{2}$ such as $\mathrm{CH}_{4}$ and $\mathrm{N}_{2} \mathrm{O}$ is not excluded in the report on the total greenhouse gas emission. In addition, a preliminary research revealed that the $\mathrm{N}_{2} \mathrm{O}$ emission of the fluidized bed boiler is quite high when compared to that of the coal-fired boiler [11]. Therefore, developing non- $\mathrm{CO}_{2}$ emission factor of biomass-using circulating fluidized bed (CFB) power plants, which is appropriate for the domestic circumstances would ensure very important basic data for the estimation and forecast of greenhouse gas emission and emission reduction plans.

\section{Designation of Subject Facilities}

Fluidized bed combustion technology is one of the most simple and environmentally friendly ways to combust solid fuel such as coal. The technology enables the temperature maintenance of the combustion furnace at $900^{\circ} \mathrm{C}$, prohibiting the creation of nitrogen oxide and directly desulfurizing inside the furnace with lime stone. The technology also enables mixed combustion of various solid fuels such as biomass and wood chip while combusting coal [12-15]. There have been consistent efforts to ensure that the technology enables fuel diversification through mixed combustion of multicarbon coal and mixed combustion of coal and other fossil fuels, and the combustion which is economically feasible and environmentally friendly.

This research selected Plant B that uses biomass as a main fuel instead of fossil fuel. The working site of Plant B operates a $50 \mathrm{MW}$ CFB power plant. Wood chip fuel (WCF) accounts for about $70 \%$ of the total fuel. Furthermore, $20 \%$ of the fuel is refused plastic fuel (RPF) which is made by processing waste synthetic resins such as vinyl into pellet type. $10 \%$ of the fuel is refused derived fuel (RDF) which is made by grinding, compressing, and molding daily wastes, creating pellet type fuel. The working site is using 22,677 ton/month of alternative fuel which is the largest compared to those of other working sites using alternative fuel except waste tires. Detailed information of using alternative fuels is shown in Table 1.

\section{Research Method}

3.1. Analysis Method of Energy Source. We collected about $1 \mathrm{~kg}$ of fuel sample when the fuels were put into the facility. The collected sample was ground with a rotating grinder. First, the sample was ground to pass a screen with $4.75 \mathrm{~mm}$
TABLE 1: Plant lists of using alternative fuels.

\begin{tabular}{lccc}
\hline & Plant name & $\begin{array}{c}\text { The amount of } \\
\text { alternative fuels } \\
\text { (ton/month) }\end{array}$ & Type of fuels \\
\hline 1 & Plant A & 27,097 & TDF* $^{*}$ \\
2 & Plant B & 22,677 & WCF, RDF, and RPF \\
3 & (study site) & 10,722 & RPF \\
4 & Plant C & 8,572 & RPF \\
5 & Plant D & 5,996 & RPF \\
6 & Plant E & 4,227 & RPF \\
\hline
\end{tabular}

*TDF: tire derived fuel.

of gradation, which is coarse grinding. Second, the sample was ground to pass a screen with $1 \mathrm{~mm}$ of gradation, which is fine grinding. Then, the ground sample was treated with the increment reduction method. The prepared sample was used to analyze its heating value. The heating value analyzing equipment used in this study was an automatic calorimeter (IKA-C2000, Germany). The equipment measures the temperature increase during the combustion of the sample, calculating the heating value per $1 \mathrm{~g}$ of sample. The heating values of energy sources are divided into gross calorific value (GCV) and net calorific value (NCV). Gross caloric value is the heating value generated during the combustion of the sample which includes the vapor and the latent heat in the combustion gas. Meanwhile, NCV excludes the vaporization heat of moisture generated during the combustion of moisture or hydrogen in the fuel. This research converted the dry-basis GCV into an NCV which is suggested by IPCC $2006 \mathrm{G} / \mathrm{L}$, by applying the content of hydrogen and moisture.

3.2. Method of Collecting Exhaust Gas Sample. In order to confirm the emission characteristics of $\mathrm{CH}_{4}$ and $\mathrm{N}_{2} \mathrm{O}$ that are released from the emission source, field surveys such as the analysis of exhaust gas flow, moisture amount, and gas sample were performed. The field survey company measured the temperature of the exhaust gas, moisture amount, air temperature, flow velocity, and pressure when it collected samples of greenhouse gas [16,17].

The temperature of the exhaust gas of the greenhouse gas emission facilities is above $100^{\circ} \mathrm{C}$ in general. Therefore, the sampling tubes and sample collecting pipes should be made of materials that can stand high temperatures and flow velocities. So, we manufactured sampling tubes made of stainless steel that can withstand high temperature and flow velocity, satisfying the Koran Standard Method $(7 \mathrm{~mm}$ of inner diameter). The length of the tube is $1.5 \mathrm{~m}$. Two tubes are linked when the inner wall or inner diameter of the stack is big. To remove the moisture included in the exhaust gas, we installed a moisture absorption bottle with silica gel in front of the equipment collecting exhaust gas so that the greenhouse gas sample did not include moisture. The moisture collecting equipment was also made of the same material as that of the sampling tube. To prevent the clogging of the filter medium caused by corrosion of 


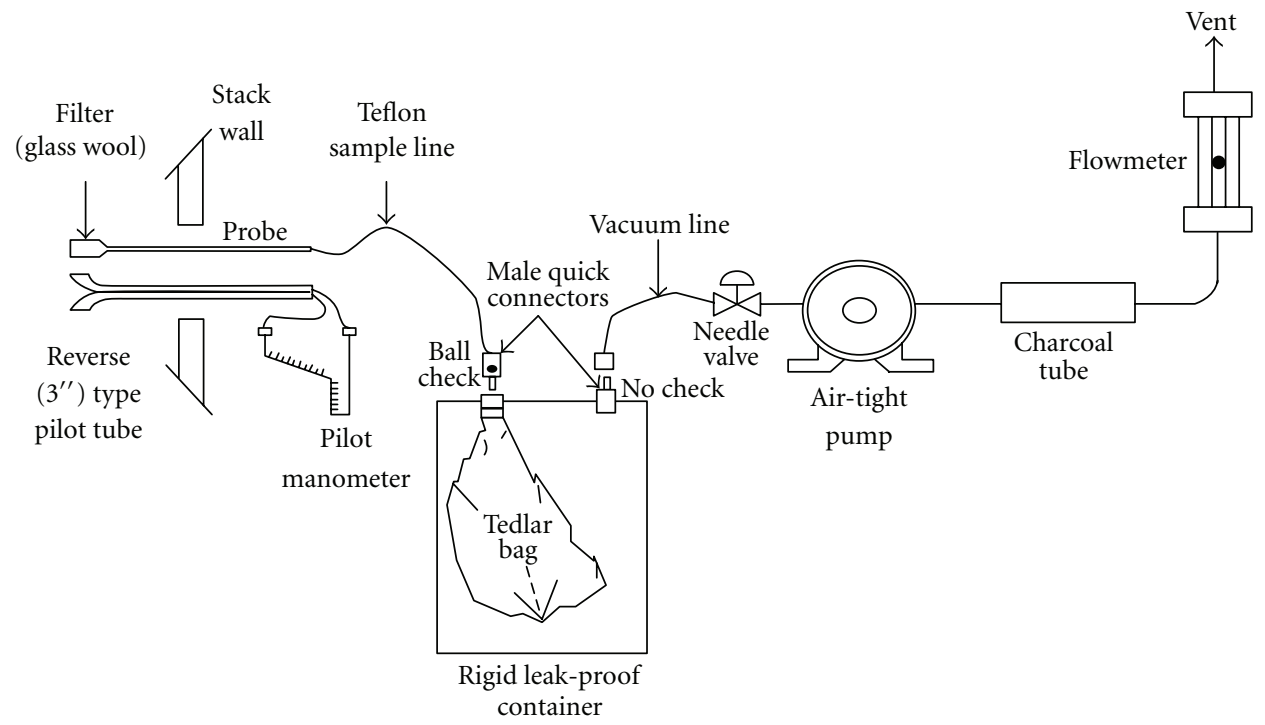

Figure 1: Greenhouse gas sampling using lung sampler.

sampling tube or pipe or moisture condensation, we heated the whole sampling tube with the electric heating method up to $120^{\circ} \mathrm{C}$, collecting moisture included in the exhaust gas with anhydride calcium hydride.

This research used $10 \mathrm{~L}$ of Tedlar bag when collecting exhaust gas samples, applying EPA method 18 [18]. The diagram is provided in Figure 1. To collect representative samples, we collected samples with 20 to 30 minutes of interval at the emission source (stack) from $10 \mathrm{AM}$ to $6 \mathrm{PM}$ for a period of five days.

\subsection{Method of Analyzing the Concentration of Non- $\mathrm{CO}_{2}$} Greenhouse Gas. We covered the light over collected samples and analyzed at a laboratory on the day of collecting. $\mathrm{CH}_{4}$ in the exhaust gas was analyzed with Gas Chromatography with Flame Ionization Detector (GC-FID). $\mathrm{CH}_{4}$ is known as a representative compound of hydrocarbon that is analyzed with GC-FID [19]. $\mathrm{N}_{2} \mathrm{O}$ was analyzed with gas chromatography and its concentration was analyzed with the electron capture detector (ECD). GC-ECD is a widely used detector for $\mathrm{N}_{2} \mathrm{O}$ and chlorofluorocarbons (CFCs).

We used $1 \mathrm{~m}$ and $3 \mathrm{~m}$ of Porapak Q 80/100 mesh packed column (Stainless steel, $3.175 \mathrm{~mm}$ external diameter, Restek) and ultrapure nitrogen as carrier gas. The flux of the carrier gas was set at $20 \mathrm{~mL} / \mathrm{min}$ and the temperatures of the injection port and oven were set at $120^{\circ} \mathrm{C}$ and $70^{\circ} \mathrm{C}$, respectively. To remove oxygen and moisture in the gas sample, we used 10,6, and 4 ports of switching valve. The detector was set at $320^{\circ} \mathrm{C}$. Detailed condition of the analysis is as shown in Table 2.

To conduct a quantitative analysis, we used $0.1,0.5,1.0$ and $5.0 \mathrm{ppm}$ of standard gas, drawing a calibration curve. The calibration curve showed a sound linearity which is $R^{2}=$ 0.9999. Figure 2 was used in analyzing the concentration of the collected sample.

To conduct a quantitative analysis, we used 0.1, 0.5, 1.0, 5.0, and $10.2 \mathrm{ppm}$ of standard gas, drawing a calibration
TABle 2: Analysis condition of GC for $\mathrm{N}_{2} \mathrm{O}$ and $\mathrm{CH}_{4}$.

\begin{tabular}{lcc}
\hline & GC/FID & GC/ECD \\
\hline Column & Porapack Q 80/100 & Parapack Q 80/100 \\
Carrier gas & $\mathrm{N}_{2}(99.999 \%)$ & $\mathrm{N}_{2}(99.999 \%)$ \\
Flow & $30 \mathrm{~mL} / \mathrm{min}$ & $20 \mathrm{~mL} / \mathrm{min}$ \\
Temperature & & \\
$\quad$ Oven & $80^{\circ} \mathrm{C}$ & $70^{\circ} \mathrm{C}$ \\
$\quad$ Injector & $100^{\circ} \mathrm{C}$ & $120^{\circ} \mathrm{C}$ \\
$\quad$ Detector & $250^{\circ} \mathrm{C}$ & $320^{\circ} \mathrm{C}$ \\
Detector range & 0 & 0 \\
\hline
\end{tabular}

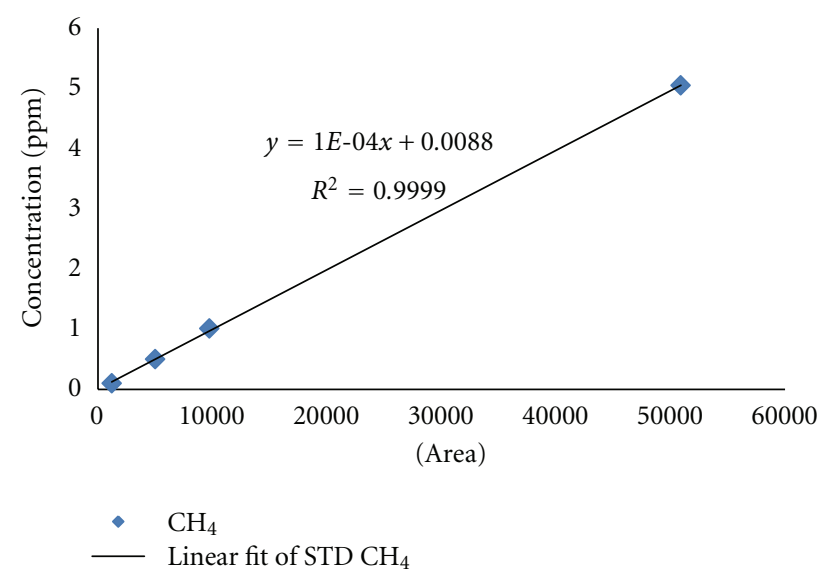

FIgure 2: Calibration curve by $\mathrm{CH}_{4}$ standard.

curve. The calibration curve showed a sound linearity which is $R^{2}=0.9998$. Figure 3 was used in analyzing the concentration of the collected sample.

3.4. Method of Calculating the Emission Factor of Non- $\mathrm{CO}_{2}$. As for $\mathrm{CO}_{2}$, highly reliable emission factors can be calculated with the element analysis of the fuel. However, the emission 


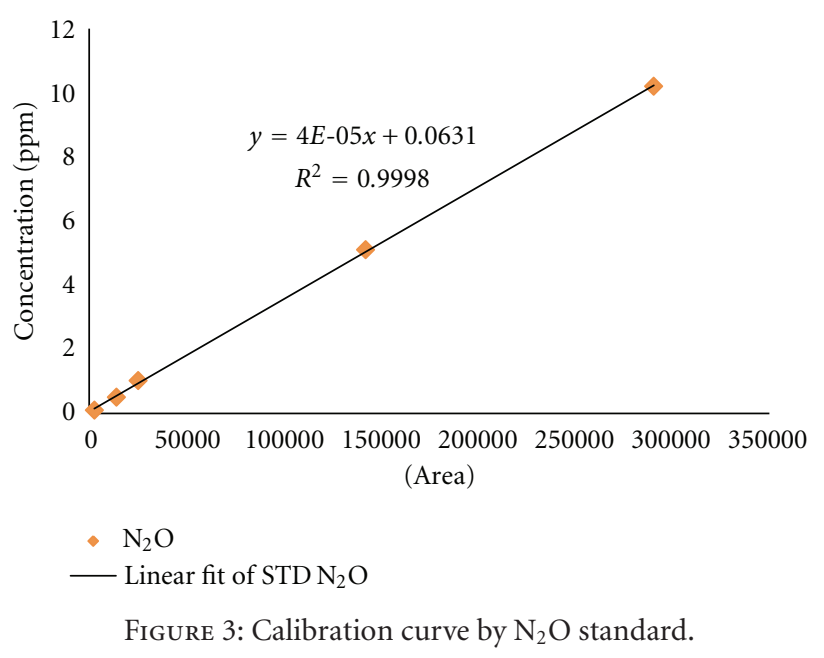

factor of non- $\mathrm{CO}_{2}$ is affected by combustion condition such as combustion technology. Therefore, the emission factor calculated based on the fuel analysis may not be used as a representative value. So, this study measured the $\mathrm{CH}_{4}$ and $\mathrm{N}_{2} \mathrm{O}$ in the exhaust gas of the CFB power plant that uses biomass as a main fuel. The worksheet of the emission factor is comprised of 5 steps, which are shown in Table 3.

First, input the contents of carbon and hydrogen that were calculated in analysis of fuel. Second, measure a GCV, and to convert GCV into NCV, applying the result of the element analysis conducted in step 1. Moreover, input the data for consumption of fuel in the field. Third, input measured concentrations of $\mathrm{CH}_{4}$ and $\mathrm{N}_{2} \mathrm{O}$ in the exhaust gas. Fourth, calculate the amount of $\mathrm{CH}_{4}$ and $\mathrm{N}_{2} \mathrm{O}$. Fifth, calculate emission factors of $\mathrm{CH}_{4}$ and $\mathrm{N}_{2} \mathrm{O}$.

\section{Result and Consideration}

4.1. Accuracy Management of the Analyzing Equipment. Table 4 shows the result of the reproducibility and the method detection limit (MDL) which is needed for the analysis accuracy management of $\mathrm{CH}_{4}$ and $\mathrm{N}_{2} \mathrm{O}$, the study subject of this paper. To evaluate the reproducibility, we analyzed the standard gases which are $1.01 \mathrm{umol} / \mathrm{mol}$ of $\mathrm{CH}_{4}$ and $1.02 \mathrm{umol} / \mathrm{mol}$ of $\mathrm{N}_{2} \mathrm{O}$, three times repetitively. As for the reproducibility, the standard error (SE) and the relative standard error (RSE) of $\mathrm{CH}_{4}$ and $\mathrm{N}_{2} \mathrm{O}$ were 18.15 and $0.18 \%$, and 125.01 and $0.291 \%$, respectively. We also measured the detection limit of at least seven samples of which concentration of the measuring item is high enough to be detected. The detection limit was calculated by multiplying the standard deviation of repetitive measurements and the distribution value $t$ of the freedom degree. Distribution value 3.143 , which is for the degree of freedom 6, was applied within $98 \%$ of reliability in the repetitive measuring of seven samples [20]. As a result, the detection limits of $\mathrm{CH}_{4}$ and $\mathrm{N}_{2} \mathrm{O}$ were $0.013 \mathrm{ng}$ and $0.074 \mathrm{ng}$, respectively.

\subsection{Fuel Characteristics of Subject Power Plant}

4.2.1. Analysis Result of Heating Value. The production and consumption of solid, liquid, and gas fuel is expressed with a physical unit such as tons in the statistics or data of energy. The heating value is needed to convert the unit into another energy unit a Joule. This study calculated each energy source's as received basis (ABS) net heating value that is used in the 2006 IPCC Guideline.

The subject working sites use wood chips made of waste wood, RDF that are made of daily wastes through grinding, compression, and molding, and RPF which is a pellet-type fuel processed from waste synthetic resins such as vinyl and plastic, as energy sources. This study collected the samples on separate dates to increase the reliability. We analyzed eight samples of each energy source. The results are shown in Table 5.

The ARB NCV of RDF, RPF, and WCF are $11.9 \mathrm{TJ} / \mathrm{Gg}$ (RSD 10.1\%), 17.1 TJ/Gg (RSD 28.9\%), and $31.2 \mathrm{TJ} / \mathrm{Gg}$ (RSD $17.9 \%$ ), respectively. The RPF of vinyl or plastic with high heating value was the highest. The RSD of the heating value of RDF- 5 or RPF was more than $20 \%$ higher than others. This is because the composition rarely remained steady when the fuel was made of wastes.

4.2.2. The Result of Element Analysis. The combustion characteristics are greatly affected by the main elements of the fuel such as carbon $(\mathrm{C})$, hydrogen $(\mathrm{H})$, nitrogen $(\mathrm{N})$, sulfur (S), and moisture (including adherent moisture and inherent moisture), ash, volatile component, and adherent carbon. In particular, $\mathrm{C}$ is involved in the generation of $\mathrm{CO}_{2}$, one of greenhouse gases, and used in calculating the heating value of the vapor created due to hydrogen. Therefore, this study analyzed the content of carbon and hydrogen in the fuel, by analyzing the elements of the energy sources used in the subject working sites. The results are shown in Table 6 . Carbon and hydrogen account for 44\% (RSD 4.4\%) and 5\%, $46 \%$ (RSD $13.9 \%$ ) and $6 \%$, and $67 \%$ (RSD $16.7 \%$ ) and $8 \%$ of the WCF, RDR-5, and RPF, respectively. The results show that there is big gap between RDF and RPF, compared to WCF.

4.3. Emission Characteristics of Non- $\mathrm{CO}_{2}$. Table 7 shows the analysis results of emission concentration of $\mathrm{CH}_{4}$ and $\mathrm{N}_{2} \mathrm{O}$ that are measured at CFB power plants using biomass and alternative fuel. The average concentration of $\mathrm{CH}_{4}$ of the exhaust gas is $2.78 \mathrm{ppm}$, with the minimum and maximum concentration ranges of $0.1 \mathrm{ppm}$ and $3.27 \mathrm{ppm}$, respectively. The analysis of 104 samples showed that the $\mathrm{SE}$ of $\mathrm{CH}_{4}$ is 0.02 . The average concentration of $\mathrm{CH}_{4}$ is $7.68 \mathrm{ppm}$, with the minimum and maximum ranges of $1.15 \mathrm{ppm}$ and $12.75 \mathrm{ppm}$, respectively. The average error is 0.22 in the analysis of 108 samples. As for the emission characteristics of the $\mathrm{CH}_{4}$ and $\mathrm{N}_{2} \mathrm{O}$, those of $\mathrm{CH}_{4}$ rarely changed at low concentration.

The emission concentration is lower than that of the power plants using fossil fuel. This is because the fuel is mixed well with the help of $\mathrm{CFB}$, unlike the general combustion method. The emission concentration of $\mathrm{N}_{2} \mathrm{O}$ is rather higher than that of power plants using fossil fuel. The combustion of CFB power plants is conducted at the relatively low temperature of $900^{\circ} \mathrm{C}$, unlike that of the fire-powered method. Previous studies indicated that $\mathrm{NOx}$ reduces at this temperature, while the emission of $\mathrm{N}_{2} \mathrm{O}$ rises (e.g., [2]). 
TABLE 3: Calculation worksheet for emission factor based on greenhouse gas measurement.

(a) Step 1 (fuel data)

\begin{tabular}{|c|c|c|c|c|c|c|}
\hline Item & $\begin{array}{c}\text { Carbon of fuel } \\
\text { (as received basis) }\end{array}$ & $\begin{array}{l}\text { Carbon of fuel } \\
\text { (air-dried basis) }\end{array}$ & $\begin{array}{c}\text { Carbon of } \\
\text { fuel } \\
\text { (dry basis) }\end{array}$ & $\begin{array}{l}\text { Inherent } \\
\text { moisture }\end{array}$ & $\begin{array}{l}\text { Total } \\
\text { moisture }\end{array}$ & Hydrogen \\
\hline Subitem & & & (1) & (2) & (3) & (4) \\
\hline Unit & $(\%)$ & $(\%)$ & $(\%)$ & $(\%)$ & $(\%)$ & $(\%)$ \\
\hline Calculation & (1) $\times((100-$ (2) $) \div 100)$ & (1) $\times((100-$ (3) $) \div 100)$ & & & & \\
\hline
\end{tabular}

(b) Step 2 (raw data)

\begin{tabular}{lcccc}
\hline Item & Gross heating value & Net heating value & Fuel consumption rate & Heating output \\
\hline Subitem & $A$ & $B$ & $C$ & $D$ \\
Unit & $(\mathrm{kcal} / \mathrm{kg})$ & $\mathrm{TJ} /$ ton & ton $/ \mathrm{h}$ & $\mathrm{TJ} / \mathrm{h}$ \\
Calculation & & $([A-\{600 \times(9 \times(3)+(4))\}] \times 4.18) \times 10^{-6}$ & & $B \times C$ \\
\hline
\end{tabular}

(c) Step 3 (non- $\mathrm{CO}_{2}$ concentration)

\begin{tabular}{lccc}
\hline Item & Volume concentration & Mass concentration & \\
\hline Subitem & $E$ & $F$ & $G$ \\
Unit & $\mathrm{ppm}$ & $\mathrm{mg} / \mathrm{m}^{3}$ & $\mathrm{~m}$ \\
Calculation & & $E \times(16$ or $44 \div 22.4)$ & \\
\hline
\end{tabular}

(d) Step 4 (non- $\mathrm{CO}_{2}$ emission) and Step 5 (non- $\mathrm{CO}_{2}$ emission factor)

\begin{tabular}{|c|c|c|}
\hline Item & Non- $\mathrm{CO}_{2}$ emission & Non- $\mathrm{CO}_{2}$ emission factor \\
\hline Subitem & $H$ & $I$ \\
\hline Unit & $\mathrm{g} / \mathrm{h}$ & $\mathrm{kg} / \mathrm{TJ}$ \\
\hline Calculation & $F \times G \div 10^{3}$ & $H \div D$ \\
\hline
\end{tabular}

TABLe 4: Test of reproducibility and method detection limit.

(a) Results of reproducibility

\begin{tabular}{lccccc}
\hline \multirow{2}{*}{ Substance } & \multicolumn{2}{c}{ Result of reproducibility test (area) } & \multicolumn{3}{c}{ Statistical data } \\
& 1 & 2 & 3 & Mean & SE \\
\hline $\mathrm{CH}_{4}$ & 9,775 & 9,767 & 9,717 & 9,753 & 18.15 \\
$\mathrm{~N}_{2} \mathrm{O}$ & 24,689 & 24,939 & 24,811 & 24,813 & 125.01 \\
\hline
\end{tabular}

aStandard error (SE): standard deviation.

(b) $\mathrm{MDL}$

\begin{tabular}{lcccccccccccc}
\hline \multicolumn{2}{c}{ Classification } & 1 & 2 & 3 & 4 & 5 & 6 & 7 & $\begin{array}{c}\text { Mean } \\
\text { SD }\end{array}$ & $\begin{array}{c}\text { MDL } \\
\text { ng }\end{array}$ \\
\hline $\mathrm{CH}_{4}$ & Peak area & 724 & 690 & 764 & 642 & 655 & 705 & 679 & 694 & 41 & 0.013 \\
$\mathrm{~N}_{2} \mathrm{O}$ & Peak area & 3,232 & 2,684 & 2,574 & 3,655 & 2,221 & 1,612 & 2,574 & 2,650 & 661 & 0.074 \\
\hline
\end{tabular}

bSD: standard deviation.

TABLE 5: Caloric value of alternative fuels for combustion.

\begin{tabular}{lccccc}
\hline Sample name & Gross calorific value (TJ/Gg) & Net calorific value (TJ/Gg) & RSD (\%) & Moisture (\%) & Number of sample (EA) \\
\hline WCF & 13.7 & 11.9 & 10.1 & 25.1 & 8 \\
RDF & 19.0 & 17.1 & 28.9 & 24.2 & 8 \\
RPF & 33.5 & 31.2 & 17.9 & 10.0 & 8 \\
\hline
\end{tabular}


TABLE 6: Elementary analysis of various fuels.

\begin{tabular}{lccc}
\hline Sample name & C $(\%)$ & H $(\%)$ & Number of sample (EA) \\
\hline WCF & 44.0 & 5.6 & 8 \\
RDF & 46.5 & 6.0 & 8 \\
RPF & 66.8 & 8.5 & 8 \\
\hline
\end{tabular}

TABle 7: Average value of $\mathrm{CH}_{4}$ and $\mathrm{N}_{2} \mathrm{O}$ concentration in the biomass fired circulating fluidized bed power plants.

\begin{tabular}{lcccccc}
\hline Sample & Mean & SD & Min. & Max. & SE $^{\mathrm{a}}$ & $N$ \\
\hline Methane & 2.78 & 0.22 & 0.10 & 3.27 & 0.02 & 104 \\
Nitrous oxide & 7.68 & 2.25 & 1.15 & 12.75 & 0.22 & 108 \\
\hline
\end{tabular}

a Standard error (SE): standard deviation $/ \sqrt{N}$.

TABLE 8: Compare with emission factors of circulating fluidized bed boiler.

\begin{tabular}{cccc}
\hline Type of fuels & $\begin{array}{r}\text { Emission factors (kg/TJ energy input) } \\
\mathrm{CH}_{4}\end{array}$ & $\mathrm{~N}_{2} \mathrm{O}$ \\
\hline \multirow{2}{*}{ This study } & $\begin{array}{c}\text { WCF, RDF, and } \\
\text { RPF }\end{array}$ & 1.2 & 3.3 \\
2006 IPCC & $\begin{array}{c}\text { Bituminous } \\
\text { Peat }\end{array}$ & 1 & 61 \\
& Peat & 3 & 7 \\
\hline
\end{tabular}

4.4. Calculation of Emission Factor of Non- $-\mathrm{CO}_{2}$. Table 8 showed that the analysis result of exhaust gas of subject facilities, energy sources, and the emission factor of $\mathrm{CH}_{4}$ and $\mathrm{N}_{2} \mathrm{O}$ that are calculated with the process data. The emission factor of $\mathrm{CH}_{4}$ of CFB power plant using biomass as a main energy source was calculated to be $1.2 \mathrm{~kg} / \mathrm{TJ}$ which is within the same range of emission factor suggested by 2006 IPCC Guideline. The emission factor of $\mathrm{N}_{2} \mathrm{O}$ is $3.3 \mathrm{~kg} / \mathrm{TJ}$ which is lower than that suggested by IPCC. Like other studies, this research also showed that the emission concentration of $\mathrm{N}_{2} \mathrm{O}$ could be reduced more when the CFB power plant uses biomass or other fuel mixed with biomass than when it uses $100 \%$ fossil fuel $[21,22]$. The IPCC suggested $61 \mathrm{~kg} / \mathrm{TJ}$ and $7 \mathrm{~kg} / \mathrm{TJ}$ as the basic emission factor of $\mathrm{N}_{2} \mathrm{O}$ released from the CFB boilers using just bituminous coal and peat, respectively. There is gap between the actual emission factor and the basic emission factor. Unlike the emission factor of $\mathrm{CO}_{2}$ of adherent combustion, those of non- $\mathrm{CO}_{2}$ such as $\mathrm{CH}_{4}$ and $\mathrm{N}_{2} \mathrm{O}$ are greatly affected by type, size, and mixing rate of combustion and the combustion technology of boilers.

4.5. Uncertainty Assessments. To produce a more reliable average value in developing a final emission factor, we used a probability method of average forecasting that is suggested by 2006 IPCC G/L. This research used Monte Carlo simulation among other forecasting methods. The Monte Carlo analysis is useful when in the detailed sector assessment of uncertainty, the uncertainty is high, distribution is irregular, algorithm is complex functions, and there is a correlation between some activities group and emission factors.

In the Monte Carlo simulation, probability density function (PDF) should be designated to rationally represent each model of uncertainty. To designate it, we carried out the goodness-of-fit test of the probability density function.

The goodness-of-fit test is the statistical inference to find out whether the sample distribution has the theoretical distribution. The null hypothesis is that the observed data comes from a specific distribution. Rejecting the null hypothesis means that the data distribution does not follow the theoretical distribution. The criterion of the rejection is determined by significant level $\alpha$ that is the maximum allowable limit of probability fallible in process of the hypothesis test. The null hypothesis is rejected when the significant probability ( $P$ value), which is calculated by a test statistic, is less than a significant level. The test statistics used in this study are Kolmogorov-Smirnov (K-S) and AndersonDarling (A-D). The K-S test is based on the empirical distribution function (ECDF). $D$ is calculated as follows:

$$
D=\max _{1 \leq i \leq N}\left(F\left(Y_{i}\right)-\frac{i-1}{N}, \frac{i}{N}-F\left(Y_{i}\right)\right),
$$

where $Y_{1}, Y_{2}, \ldots, Y_{N}$ are $N$-ordered data points, and $F$ is the theoretical cumulative distribution.

$\mathrm{K}-\mathrm{S}$ test has an advantage in which $D$ is not affected by a cumulative distribution function of the theoretical distribution and it is an exact test. Meanwhile, it tends to be more greatly affected by the center than the tail in the distribution. In addition, the parameters of the distribution should be fully specified.

A-D statistic could be used in several distributions where weak points of the K-S should be considered, and adds more weight on the tail than the K-S does. The test statistic, $A^{2}$, is as follows:

$$
\begin{gathered}
A^{2}=-N-S, \\
S=\sum_{i=1}^{N} \frac{(2 i-1)}{N}\left[\ln F\left(Y_{i}\right)+\ln \left(1-F\left(Y_{N+1-i}\right)\right)\right],
\end{gathered}
$$

where $Y_{1}, Y_{2}, \ldots, Y_{N}$ are $N$-ordered data points, and $F$ is the theoretical cumulative distribution.

All tests were realized by applying statistical program " $R$ " (ver. 2.12.0) and the significant level was 5\%. We determined the probability density function by a goodness-of-fit test of emission concentration of $\mathrm{CH}_{4}$ and $\mathrm{N}_{2} \mathrm{O}$, emission flux, fuel consumption, and low heating value of the fuel which are the data necessary to calculate the emission factors of $\mathrm{CH}_{4}$ and $\mathrm{N}_{2} \mathrm{O}$. The result is shown in Table 9. The data set was randomly generated 5,000 times from the appropriate probability density function using the Cristal Ball software of Monte Carlo simulation. The result is shown in Figure 4. The emission factors of $\mathrm{CH}_{4}$ and $\mathrm{N}_{2} \mathrm{O}$ that are calculated in the Monte Carlo simulation are $1.4 \mathrm{~kg} / \mathrm{TJ}(0.9-1.9 \mathrm{~kg} / \mathrm{TJ})$ and $4.0 \mathrm{~kg} / \mathrm{TJ}(2.9-5.3 \mathrm{~kg} / \mathrm{TJ})$, respectively, within the reliability range of $95 \%$.

\section{Result}

This study analyzed the fuel of CFB boiler using wood biomass as a main fuel with a percentage of $70 \%$, measuring the concentration of $\mathrm{CH}_{4}$ and $\mathrm{N}_{2} \mathrm{O}$ in the exhaust gas to 


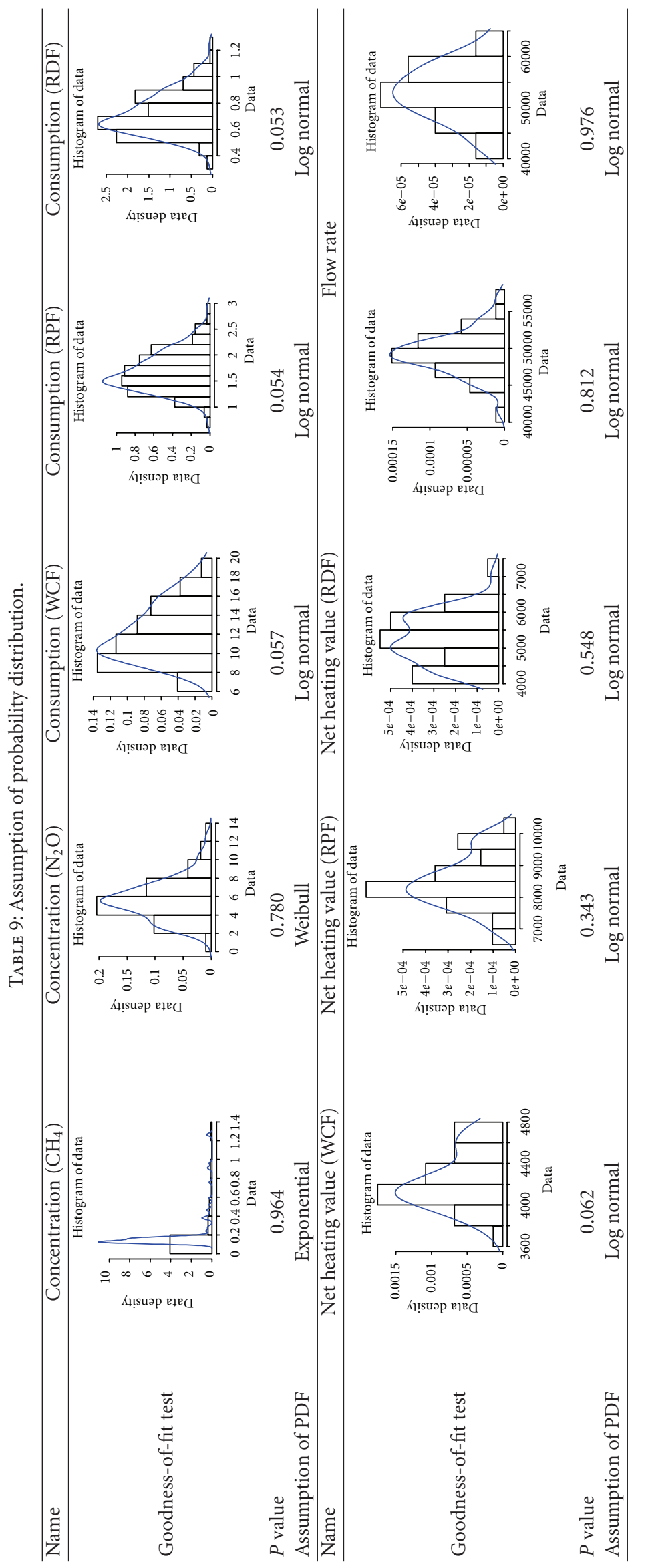




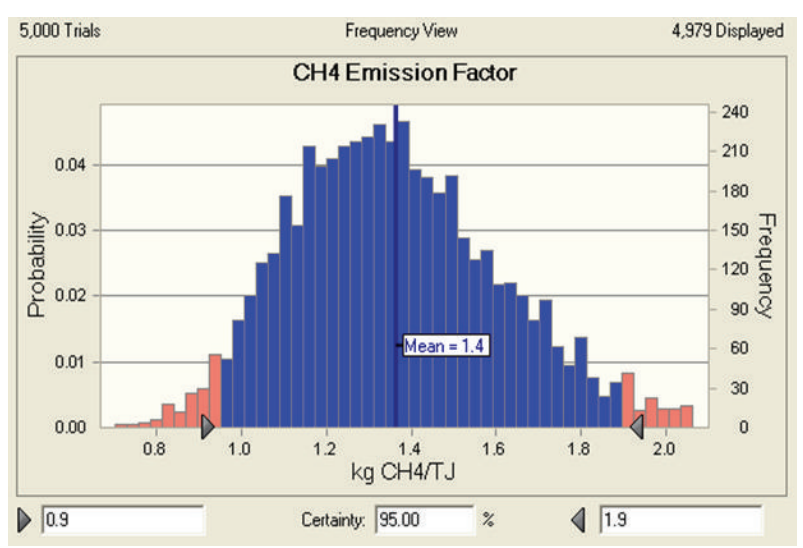

(a)

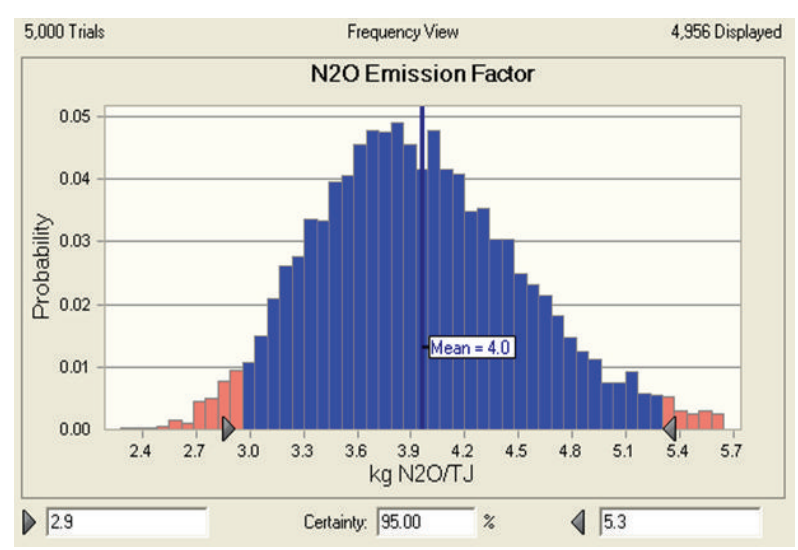

(b)

Figure 4: The result of Monte Carlo simulation on $\mathrm{CH}_{4}$ and $\mathrm{N}_{2} \mathrm{O}$ emission factors.

calculate their emission factors. The subject working sites use WCF, RPF, and RDF as fuels. The fuel analysis showed that the ARBs of WCF, RDF, and RPF are $11.9 \mathrm{TJ} / \mathrm{Gg}$ (RSD $10.1 \%$ ), $17.1 \mathrm{TJ} / \mathrm{Gg}$ (RSD 28.9\%), and $17.9 \mathrm{TJ} / \mathrm{Gg}$ (RSD $17.9 \%)$, respectively. The heating value of the RPF using vinyl and plastic of which heating value is high was the highest. The concentration analysis showed that the average concentration of $\mathrm{CH}_{4}$ is $2.78 \mathrm{ppm}$ within the minimum and maximum ranges of $0.1 \mathrm{ppm}$ and $3.27 \mathrm{ppm}$, respectively. The SE of the average concentration is 0.02 , which is the result of analyzing 104 samples. In addition, the average concentration of $\mathrm{N}_{2} \mathrm{O}$ is $7.68 \mathrm{ppm}$ within the minimum and maximum ranges of $1.15 \mathrm{ppm}$ and $12.75 \mathrm{ppm}$, respectively. Its $\mathrm{SE}$ is 0.22 , which is the result of analyzing 108 samples.

We used the analysis result and the data collected in the field survey to calculate the emission factor of $\mathrm{CH}_{4}$ and $\mathrm{N}_{2} \mathrm{O}$ of the CFB boiler using biomass. The calculated emission factor of $\mathrm{CH}_{4}$ was $1.4 \mathrm{~kg} / \mathrm{TJ}(0.9-1.9 \mathrm{~kg} / \mathrm{TJ})$ within the reliability range of $95 \%$, which is in the same range as the basic emission factor suggested by 2006 IPCC Guideline. The emission factor of $\mathrm{N}_{2} \mathrm{O}$ was $4.0 \mathrm{~kg} / \mathrm{TJ}(2.9-5.3 \mathrm{~kg} / \mathrm{TJ})$ within the reliability range of $95 \%$. The emission factor is lower than that suggested by IPCC. This is because unlike the emission factor of $\mathrm{CO}_{2}$ in the adherent combustion, those of non- $\mathrm{CO}_{2}$ such as $\mathrm{CH}_{4}$ and $\mathrm{N}_{2} \mathrm{O}$ are greatly affected by type, size, and mixture portion of fuel, and the combustion technology of the boiler.

This study compared the IPCC emission factor and the emission factor calculated in this research, which indicated that the combustion technology of CFB boiler using biomass could greatly reduce $\mathrm{N}_{2} \mathrm{O}$ emission, compared to that of fossil fuel.

\section{Acknowledgments}

This subject was supported by Korea Ministry of Environment as "Climate Change Correspondence R\&D Program" This work was also supported by the Human Resources Development of the Korea Institute of Energy Technology Evaluation and Planning (KETEP) Grant funded by the
Korea government Ministry of Knowledge Economy (no. 20100092).

\section{References}

[1] IPCC, Climate Change 2007: Synthesis Report, Contribution of Working Groups I, II and III to the Fourth Assessment Report of the Intergovernmental Panel on Climate Change, 2007.

[2] S. Monni, S. Syri, and I. Savolainen, "Uncertainties in the Finnish greenhouse gas emission inventory," Environmental Science and Policy, vol. 7, no. 2, pp. 87-98, 2004.

[3] G. L. Cho, "Assessment and Implications of the National Target in Reducing Greenhouse Gases," 2010.

[4] M. Fabritius, S. Korhonen, and H. Hoffren, " $\mathrm{N}_{2} \mathrm{O}$ and $\mathrm{CH}_{4}$ emissions from different power plant processes," in Proceedings of the 3rd International Symposium on Non-CO2 Greenhouse Gases: Scientific Understanding, Control Options and Policy Aspects, J. van Ham, A. P. M. Baede, R. Guicherit, and J. G. F. M. Williams-Jacobse, Eds., pp. 67-72, Mill Press, Maastricht, The Netherlands, January 2002.

[5] S. Korhonen, M. Fabritius, and H. Hoffren, Methane and Nitrous Oxide Emissions in the Finnish Energy Production. Fortum Power and Heat, Oy, Helsinki, Finland, 2001.

[6] IPCC, "The 2006 IPCC guidelines for National Greenhouse gas inventories," in Stationary Combustion, vol. 2 of Energy, chapter 2, 2006.

[7] J. Roy, P. Sarkar, S. Biswas, and A. Choudhury, "Predictive equations for $\mathrm{CO}_{2}$ emission factors for coal combustion, their applicability in a thermal power plant and subsequent assessment of uncertainty in $\mathrm{CO}_{2}$ estimation," Fuel, vol. 88, no. 5, pp. 792-798, 2009.

[8] E. C. Jeon, S. Myeong, J. W. Sa, J. Kim, and J. H. Jeong, "Greenhouse gas emission factor development for coal-fired power plants in Korea," Applied Energy, vol. 87, no. 1, pp. 205210,2010 .

[9] IPCC, Revised 1996 IPCC Guidelines for National Greenhouse Gas Inventories, vol. 3 of Reference Manual, Energy, 1997.

[10] U. A. Schneider and B. A. McCarl, "Economic potential of biomass based fuels for greenhouse gas emission mitigation," Environmental and Resource Economics, vol. 24, no. 4, pp. 291312, 2003.

[11] E. Tsupari, S. Monni, K. Tormonen, T. Pellikka, and S. Syri, "Estimation of annual $\mathrm{CH}_{4}$ and $\mathrm{N}_{2} \mathrm{O}$ emissions from fluidised 
bed combustion: an advanced measurement-based method and its application to Finland," International Journal of Greenhouse Gas Control, vol. 1, no. 3, pp. 289-297, 2007.

[12] S. W. Grass and B. W. Jenkins, "Biomass fueled fluidized bed combustion: atmospheric emissions, emission control devices and environmental regulations," Biomass \& Bioenergy, vol. 6, no. 4, pp. 243-260, 1994.

[13] G. Piao, S. Aono, M. Kondoh, R. Yamazaki, and S. Mori, "Combustion test of refuse derived fuel in a fluidized bed," Waste Management, vol. 20, no. 5-6, pp. 443-447, 2000.

[14] M. Urciuolo, R. Solimene, R. Chirone, and P. Salatino, "Fluidizedbed combustion and fragmentation of wet sewage sludge," Experimental Thermal and Fluid Science, vol. 43, pp. 97-104, 2012.

[15] N. Rangel and C. Pinho, "Kinetic and diffusive data from batch combustion of wood chars in fluidized bed," Biomass and Bioenergy, vol. 35, no. 10, pp. 4124-4133, 2011.

[16] Ministry of Environment in Korea, Experiments For the Examination of Air Pollutions, 2004.

[17] G. D. Wight, Fundamentals of Air Sampling, Lewis, Chelsea, Mich, USA, 1994.

[18] US EPA, "Promulgated method 18," 2001, http://www.epa .gov/ttn/emc/.

[19] K. R. Kim, Measurements for Greenhouse Gases, Measuring Techniques for Air Pollutant, Korean Society for Atmospheric Environment, 1999.

[20] National Institute of Environmental Research in Korea, QA/QC Handbook for the Environmental Pollutants Analysis and Sampling Techniques, 2011.

[21] B. Leckner, L. E. Åmand, K. Lücke, and J. Werther, "Gaseous emissions from co-combustion of sewage sludge and coal/ wood in a fluidized bed," Fuel, vol. 83, no. 4-5, pp. 477-486, 2004.

[22] B. X. Shen, T. Mi, D. C. Liu, B. Feng, Q. Yao, and F. Winter, " $\mathrm{N}_{2} \mathrm{O}$ emission under fluidized bed combustion condition," Fuel Processing Technology, vol. 84, no. 1-3, pp. 13-21, 2003. 


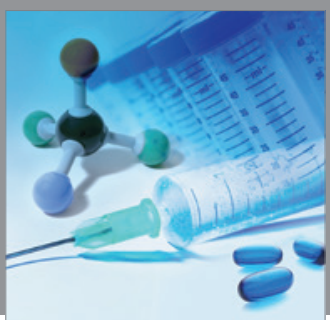

International Journal of

Medicinal Chemistry

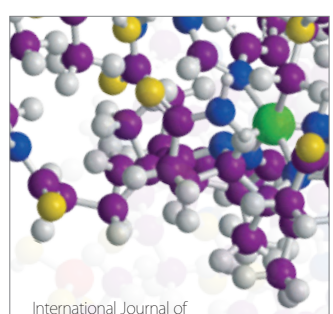

Carbohydrate Chemistry

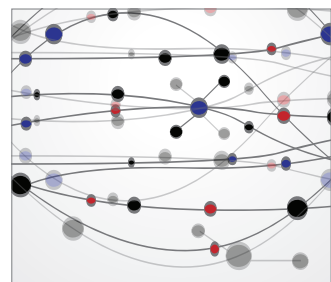

The Scientific World Journal
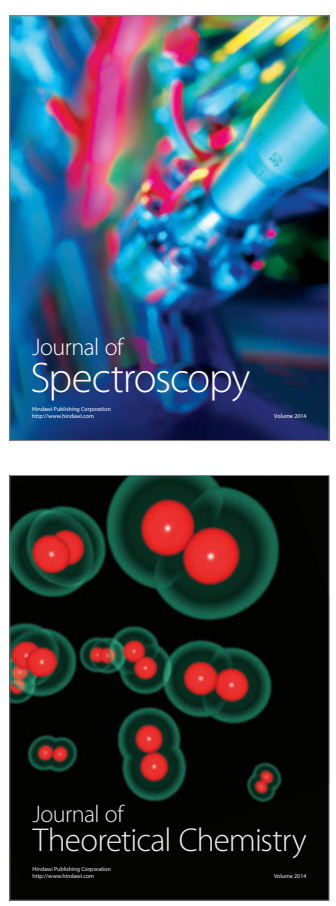
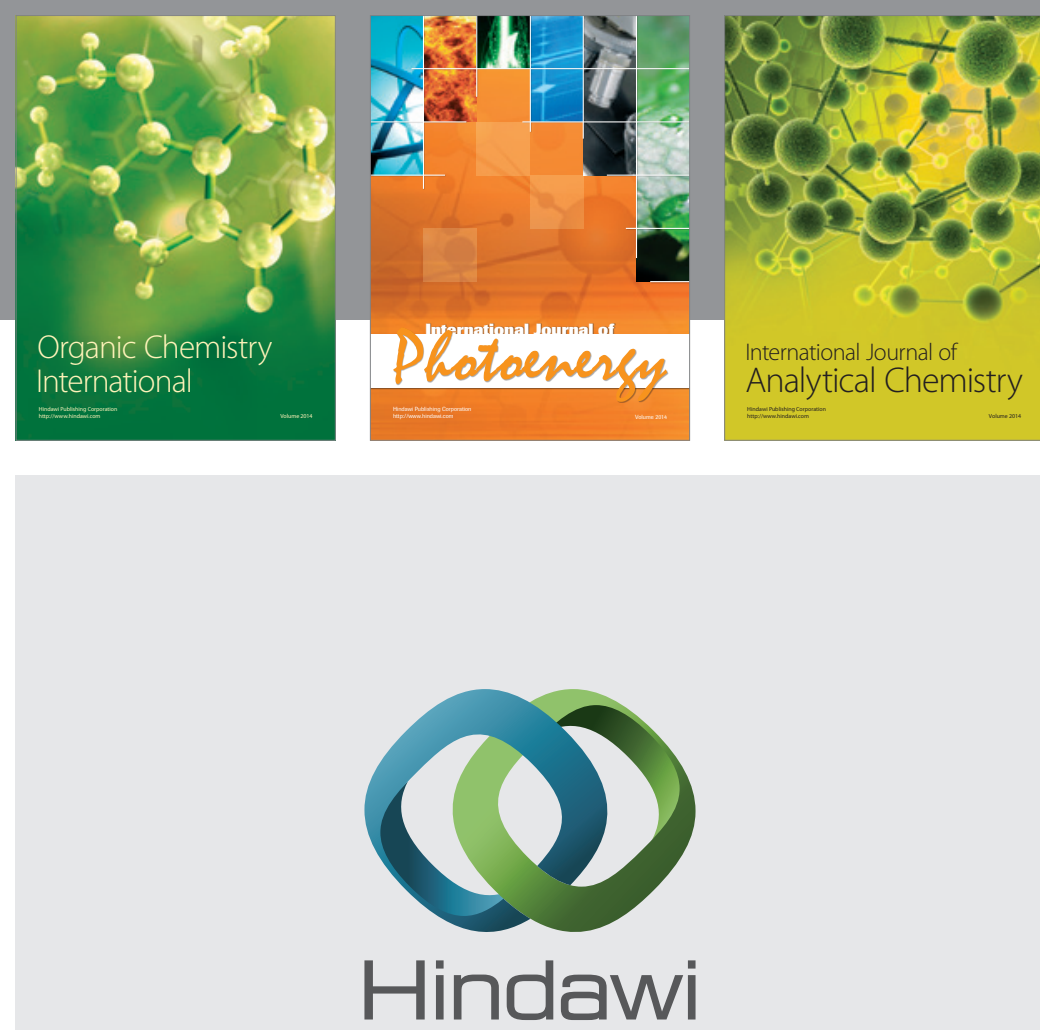

Submit your manuscripts at

http://www.hindawi.com
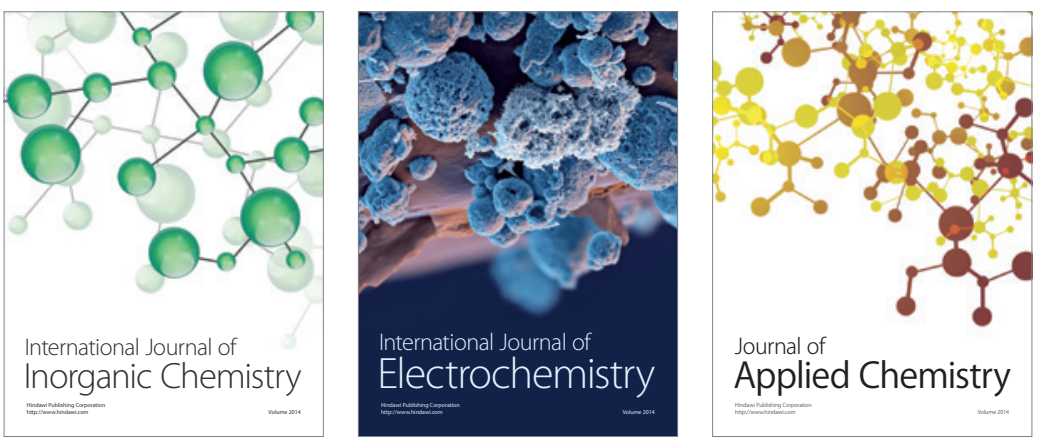

Journal of

Applied Chemistry
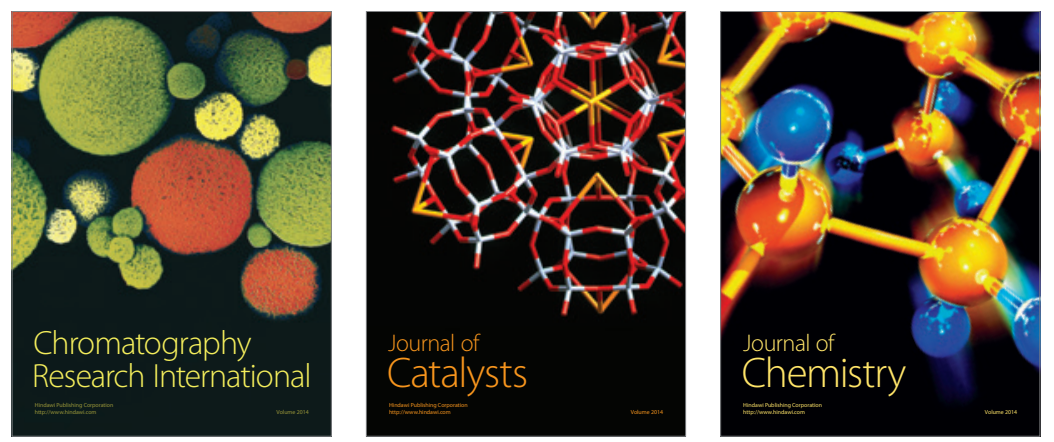
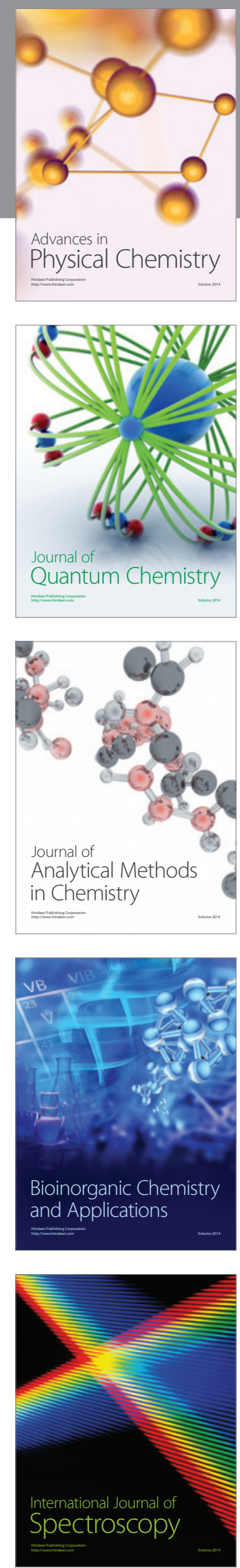